\title{
Research on Diversified Assessment Model of Peer Instruction Case Study of College Physics Course
}

\author{
Xianming $\mathrm{Liu}^{\mathrm{a}}$, Yanjun $\mathrm{Gao}^{\mathrm{b}}$ and Cheng $\mathrm{Hu}^{\mathrm{c}}$ * \\ School of Sciences, Hubei University for Nationalities, Enshi, Hubei 445000, China \\ aliuxianming1980@163.com, bgaoyjjwc@sina.com, enshihucheng@163.com
}

Keywords: College Physics; Course Teaching; Peer Instruction; Diversified; Assessment Model

\begin{abstract}
As the training objective of university talents changes, the measurement of teachers' teaching quality is no longer referenced by teachers' completion of teaching tasks but students' comprehensive knowledge application ability, which is combined with students' learning attitudes, test results and knowledge application abilities. The original teacher-based model can no longer adapt to the university development obviously, let alone meet the current needs of innovative talent development. The college physics introduces peer instruction to the teaching, establishes student-based teaching model, optimizes the teaching resources in physics class, gives play to students' teaching guidance for them to think more independently, deepen understandings of physics concept, principles and other basic theories, and comprehend physics questions by analogy. As a result, the teaching quality of college physics will be improved and the learning quality of students will be enhanced. Taking college physics course as an example, this paper studies the diversified assessment model of peer instruction.
\end{abstract}

\section{Introduction}

In China, the teaching of college physics has the deficiency of priority to theory and neglect of application. For this deficiency, the famous Chinese physicist Qian Xuesen and famous Chinese mathematician Shing-Tung Yau proposed that China did not carry out education according to the cultivation model of technological innovative talents, so no outstanding talents would be cultivated, resulting in Chinese universities did not cultivate outstanding talents and the declines in school spirits and student cultivation. Application of peer instruction in class teaching of college physics has changed the traditional teaching model, and the interactive teaching is applied to physics class. Through the interaction between teachers and students together with the interaction between students, students' self-inquiry spirits have been stimulated to acquire knowledge independently. To improve students' physics achievement, it is necessary to focus on peer instruction, establish the diversified assessment model, so that the physics class becomes more lively and interesting. As a result, it not only cultivates students' ability to explore physics problems, but also optimizes the teaching effects.

\section{Understanding of Peer Instruction}

Operation Methods for Peer Instruction. Different from the traditional teaching, peer instruction is to interact with students by using the voting system. When teaching the knowledge points, it does not carry out theoretical teaching as the traditional teaching. Instead, according to the test questions of theoretical design, it allows students to discuss the knowledge points while thinking and find answers to questions. Teachers allow students to discuss the questions and then tell the answer to teachers. Teachers determine theories needing to explain in the next link according to the accuracy rate of answers, in order to deepen students' understanding of theoretical knowledge. By adopting peer instruction, teachers can guide students to actively participate in class teaching and positively think about questions raised by teachers[1]. In addition, peer instruction can also narrow the distance between teachers' desired teaching effects and students' comprehension of knowledge. Students discuss the questions raised by teachers, and the discussion process is actually the mutual learning 
process. Students' interests in exploring unknown knowledge are stimulated, not only guiding students to learn independently but also enhancing their independent learning ability. Therefore, students are able to independently analyze and solve questions based on the acquired knowledge.

Classification of Peer Instruction. Foreign researches on peer instruction are relatively perfect and it is also relatively systematic in the specific implementation. According to the study, peer instruction can be divided into three categories:

The first is to study the effects of peer instruction in different teaching links, including effects of peer discussions, effects of teachers' participation in guidance, asking students to do the test, as well as assessment for students' test results. Some researchers suggest that peer instruction can help transform students learning concepts. When realizing the need to make efforts for better study, students will also gain returns by themselves. Discussion matters not because of correct or wrong discussion results but because of the discussion process. Even students do not get the correct answer after discussion, and teachers do not play their due role in student discussion.

The second is that university teachers apply peer instruction according to class teaching needs, do not rigidly adhere to inherent peer instruction model, but improve the peer instruction according to the class teaching contents and students' participation conditions.

The third is to introduce peer instruction to university class teaching and compare teaching quality of peer instruction with other class teaching models[2].

\section{Assessment Model in Diversified Class}

Classification of Class Assessment Model. Classroom assessment consists of three models, namely, assessment of learning (summative assessment), assessment for facilitating learning (formative assessment) and assessment as learning.

Assessment of learning focuses on exam scores, which is to assess students' learning outcomes through exams and hence the name of "summative assessment". Assessment of students learning can be ranked according to exam scores and divided into different levels. Assessment results of learning have a direct impact on the future development of students.

Assessment for facilitating learning is to assess the whole student learning process. The whole process assessment is adopted to timely provide teachers or students with feedback information, so that teachers will make the appropriate adjustments and students can adjust their learning status according to the information. Therefore, assessment for facilitating learning can enable teaching and learning to keep up with the pace of social development.

Assessment of learning belongs to the formative assessment. Compared with assessment for facilitating learning, it pays attention to the learning process, self-assessment and mutual assessment of students. Taking various assessments into comprehensive consideration, combine subjective assessment with student learning, and equate assessment to learning.

Build Diversified Class Assessment Model. According to the traditional teaching model, students' learning quality is mainly assessed by exam scores. Since the training objective of university talents changes, the practical teaching model should be changed accordingly. University class teaching will become more perfect by building the diversified class assessment model and combining with practical strategies. The diversified class assessment model is mainly built through four steps:

First Step: PI interactive teaching

In the class of college physics, PI interactive teaching includes four parts: interaction before class, interaction during class teaching, interaction after class and assessment interaction.

Interaction before class: Show the teaching outline to students within 15-20 minutes before class, so that students can understand the teaching contents and then put forward their sights, and teachers can fully know about the students' mastery of knowledge based on feedback information. Physics teachers shall correctly deal with the learning difficulties of students, and accordingly shift the teaching methods and contents of college physics according to difficulties existed in students' 
self-learning. In the teaching, mastery of the key teaching points will make students apprehend the knowledge more easily, so that it does not need to be changed.

Interaction during class teaching: Teachers may divide class teaching into several parts. At the beginning of each part, teachers tell the main teaching contents to students, organize the examination, and receive answers from students by virtue of the class response system. If the accuracy rate of students' answer is low, teachers should build the discussion team, provide appropriate guidance to student discussion, and ask students to continue discussion for getting answers. While thinking about the answers, students shall promptly discover their own mistakes, and throw themselves into learning activities from the perspective of interests; teachers should observe students' learning situation and provide the necessary assistance to facilitate student learning, listening and understanding of basic theoretical knowledge, so that student discussion and interaction in the college physics class become more substantive.

Interaction after class: Build the effective teacher-student communication platform, so that students can review independently and preview the key teaching points in next class independently.

Assessment interaction: Not perform traditional examination and assessment model, but try to use new assessment model. For example, penetrate the assessment throughout the whole college physics education, and transform the entirely closed-book examination into open-book assessment model, so that students will be more concerned about the assessment model during the usual study and get ready to accept the assessment[3].

In the specific assessment operations, teachers can conduct open-book assessment over students within two weeks before the exam. Students write the reference information for answers on the paper, including formulas and reference, and submit papers to teachers. In the exam, students can bring the prepared reference materials into the examination room for finding answers easier. Teachers may systematically analyze and assess the students' learning situation according to the reference information. This assessment approach helps urge students to study seriously, whereas students can make adjustments for their own learning model according to the assessment, so as to improve their learning efficiency.

Second Step: Incorporate assessment into student discussion

Traditional physics education model has changed, so every teaching link involves the key teaching contents. Teaching contents are taught in the form of questions, and students seek answers through mutual discussion. When most answers given by students are not correct enough, teachers may allow other students to complement and give their own answers.

The process of students answering questions is the self-assessment process of their learning conditions. When receiving questions from teachers, students will quickly search the related mastered knowledge in their brain. Based on this, students will seek correct answers by looking up information, so as to obtain information and to give empirical answer.

The answer given by a student becomes a question for other students to discuss. At this time, the student may also participate in discussion, explain the reasons for the answer, describe the acquired information, and listen to statement of others. During listening, students continuously reflect upon the opinions and measure the similarities and differences between their own answers and other opinions. After comparisons and thinking, they will get a new answer.

The assessment process is to promote learning by means of assessment. Students learn in the assessment process, so that they can think actively and seek answers independently. Their thinking abilities are no longer confined to the standard answer on textbook. Instead, they will think critically and answer from a dialectical aspect, indicating that students enhance their cognitive level about things.

When the discussions end, teachers will announce the answer. On seeing the answer, students will compare the answer with their own answer, and directly feedback their own opinions and views to teachers. According to the answer given by teachers, students will be able to judge their own learning and determine the learning direction. When students' learning motivation is activated, they will enter the independent learning stage. 
Third Step: Classroom discussion facilitate students to assess their own learning

When students assess themselves, they are playing the subjective role. Students answer the questions raised by teacher and judge according to their actual conditions, which is a self-assessment process in fact. Within two weeks after self-assessment, students will adjust their learning model, establish the desired learning level, bridge the gap between existing learning level and desired learning level through self-improvement, and thus adjust the self-learning conditions through self-assessment, in order to improve the learning state.

Fourth Step: Concentration on assessment results enables students to lay more emphasis on learning process. To help students fully understand their own performance, teachers shall build an information feedback channel, so that teachers may promptly receive the feedback information of learning progress. If the summative assessment is to assess students' learning results, then process assessment is to assess the learning effects of students. Process assessment and summative evaluation are complementary, which can provide students with an opportunity to promote learning. Therefore, in college physics education, teachers should not only pay attention to assessment of mid-term and final examinations but also offer students tests in each class. These tests shall be closely related to the teaching content in class, so that students are learning while thinking about and answering questions. It can prevent students from cramming learning before exam[4]. Furthermore, process tests can also urge students to timely review and gain new insights.

\section{Diversified Assessment Model Based on Peer Instruction can Receive Good Teaching Effect}

In college physics education, the so-called traditional physics education model means that emphasis is laid on physics teachers' teaching, students listen to teachers in class and the physics exam score is a measurement standard for the learning quality of physics. College physics is closely related with practice, and the teaching contents are interesting and vivid. Nevertheless, in the traditional teaching, students do not have the opportunity of active thinking, leading students to be passive in thinking about physics questions, not to mention giving play to creative spirits in physics learning.

The 18th National Congress of the CPC brings China to the development track of further deepening the reform and opening up, clearly states that China shall focus on cultivating applied talents, and in particular, China's engineering colleges shall change from cultivating research-oriented talents to cultivating application-oriented talents, so that students can effectively apply their acquired knowledge. College physics is a compulsory course for most science and engineering students. If the traditional physics education model is still used and the current talent cultivation requirements are not followed, the teaching philosophy will lag behind the times[5].

In recent years, many American universities start to apply peer instruction to university teaching, and some Chinese universities also adopt peer instruction as a key teaching method in universities. Although specific application of peer instruction does not attain the desired effect, it is a great progress compared with traditional college physics education. At present, the major issue for application of peer instruction in college physics education lies in that teachers do not follow the knowledge demands of students and still adhere to teacher-based teaching. Students are led by teachers in learning, inevitably leading to psychological sense of exclusion. By building diversified assessment model, it can provide reference to choose effective teaching model for the teaching of college physics with practical application. College physics teachers shall not only emphasize the importance of basic theories, but also give opportunities to students for applying theories, so that the physics learning effects will be enhanced.

\section{Conclusion}

In conclusion, while applying peer instruction to the college physics education, physics teachers shall leave the class to students, and raise questions related to the teaching contents in class as the guidance, so that students can think about questions, look up information and get answers through discussion. As a result, students' knowledge exploration spirit will be stimulated, and they will actively 
participate in learning. Teachers shall assess the performance of students, guide them to adjust and improve their learning model accordingly, and thus enhance the learning quality.

\section{Acknowledgements}

This work is supported by the Educational Commission of Hubei University for Nationalities (Grant No. 2013JYZ04)

\section{References}

[1] David J. Nicol \& James T. Boyle. Peer Instruction versus Class-wide Discussion in Large Classes: a comparison of two interaction methods in the wired classroom $[\mathrm{J}]$. Studies in Higher Education, 2010, 8(25) : 124-129.

[2] Gok,T. The impact of peer instruction on college students' beliefs about physics and conceptual understanding of electricity and magnetism $[\mathrm{J}]$. International Journal of Science And Mathematics Education, 2012, 10 (02) : 417-436.

[3] Black. Developing the theory of formative assessment, Educational Assessment, Educational Assessment Assessment and Accountability [J]. Studies in Higher Education, 2011, 21 (01) : 5-31.

[4] Kalman - C.S.M Milner-Bolotin, Antimirova, Comparison of the effectiveness of collaborative groups and peer instruction in a large introductory physics course for science majors [J]. Canadian Journal of Physics, 2010, 88 (01) : 325-332.

[5] Julie Cogill. A Model of Pedagogical Change for the Assessment of Interactive Whiteboard Practice [J]. InfoCci-Media and Communication Science and Technology, 2011 (17) : $88-96$. 